\title{
Mecanismos de abertura do sulco e da adubação nitrogenada em arroz de terras altas ${ }^{1}$
}

\author{
Vagner do Nascimento ${ }^{2}$, Orivaldo Arf ${ }^{3}$, Marlene Cristina Alves ${ }^{4}$, Carolina dos Santos Batista Bonini ${ }^{4}$, \\ Flávio Hiroshi Kaneko ${ }^{2}$, Marcelo Carvalho Minhoto Teixeira Filho ${ }^{* *}$
}

\begin{abstract}
RESUMO
A cultura do arroz adapta-se pouco ao sistema plantio direto (SPD) em razão da maior compactação da camada superficial do solo, devido ao intenso tráfego de máquinas e não mobilização do solo. Nesse caso, o mecanismo utilizado na semeadora para a abertura dos sulcos com a finalidade de deposição do adubo pode ter grande importância para facilitar a penetração das raízes e aumentar a porosidade do solo. Diante disso, propôs-se este estudo com o objetivo de avaliar o desenvolvimento e a produtividade do arroz de terras altas em sistema plantio direto, em razão de mecanismos de distribuição do adubo na semeadura e de doses de N em cobertura, em Selvíria, Mato Grosso do Sul. O delineamento experimental utilizado foi em blocos casualizados, utilizando-se um esquema fatorial 2 x 6 , constituído por mecanismos de distribuição do adubo (haste escarificadora e disco duplo) e de doses de $\mathrm{N}$ em cobertura $(0,25,50,75$, 100 e $125 \mathrm{~kg} \mathrm{ha}^{-1}$ ), com quatro repetições. Concluiu-se que os mecanismos de distribuição do fertilizante não interferiram na produtividade de grãos do arroz de terras altas; o mecanismo do tipo haste escarificadora promoveu maior altura de plantas e maior número de grãos cheios nos dois anos de cultivo; a aplicação de nitrogênio em cobertura interferiu em algumas características agronômicas, produtivas e em componentes de rendimento de engenho; a produtividade do arroz aumentou até a dose de $69 \mathrm{~kg} \mathrm{ha}^{-1}$ de $\mathrm{N}$, no primeiro ano de cultivo.
\end{abstract}

Palavras-chave: Oryza sativa L., disco duplo, haste escarificadora, plantio direto.

\section{ABSTRACT}

\section{Furrow opening implements and nitrogen fertilization in upland rice}

The rice crop has poor adaptation to the no till (NT) system because of the higher topsoil compression caused by the intense machine trafficking and reduced tillage operations. In this case, the implement used for opening furrows for fertilizer application is important to facilitate the root penetration and increase soil porosity. This study evaluated the performance and yield of upland rice in no till system as a function of the implements used for fertilizer application at sowing and $\mathrm{N}$ rates in Selvíria (MS), Brazil. The experiment was arranged in a randomized block design, using a 2 x 6 factorial arrangement, consisting of two fertilizer distribution implements (chisel plow and double disc plough) and six rates of topdress nitrogen $\left(0,25,50,75,100\right.$ and $\left.125 \mathrm{~kg} \mathrm{ha}^{-1}\right)$ with four replicates. The implements of fertilizer application did not affect the rice yield. The chisel plow provided higher plant height and number of filled grains in the two years of cultivation. The topdress nitrogen application affected some agronomic characteristics, production and milling yield components; the rice yield increased up to of the rate $69 \mathrm{~kg} \mathrm{ha}^{-1}$ of $\mathrm{N}$, in the first crop year.

Key words: Oryza sativa L., double disc plough, chisel plow, no-tillage.

\footnotetext{
Recebido para publicação em 05/12/2012 e aprovado em 14/06/2013.

${ }^{1}$ Parte do trabalho de graduação do primeiro autor. Projeto financiado pela FAPESP e pelo CNPq.

${ }^{2}$ Engenheiros-Agrônomos, Mestres. Departamento de Fitotecnia, Tecnologia de Alimentos e Sócio-Economia, Universidade do Estado de São Paulo, Campus de Ilha Solteira, Rua Monção, 226, Zona Norte, 15385-000, Ilha Solteira, São Paulo, Brasil. vagnern@gmail.com; fhkaneko@ hotmail.com

${ }^{3}$ Engenheiro-Agrônomo, Doutor. Departamento de Fitotecnia, Tecnologia de Alimentos e Sócio-Economia, Universidade do Estado de São Paulo, Campus de Ilha Solteira, Rua Monção, 226, Zona Norte, 15385-000, Ilha Solteira, São Paulo, Brasil. arf@agr.feis.unesp.br

${ }^{4}$ Engenheiros-Agrônomos, Doutores. Departamento da Faculdade de Engenharia, Universidade do Estado de São Paulo, Campus de Ilha Solteira, Rua Monção, 226, Zona Norte, 15385-000, Ilha Solteira, São Paulo, Brasil. mcalves@agr.feis.unesp.br; carolsbatistabonini@hotmail.com; mcmtf@yahoo.com.br (*autor para correspondência).
} 


\section{INTRODUÇÃO}

O sistema plantio direto (SPD) é um sistema de produção agrícola em que a semeadura da cultura é feita sem preparo do solo, mantendo os restos culturais dos cultivos anteriores na superfície. Como não há revolvimento do solo, pode ocorrer a formação de camadas compactadas na distribuição das pressões exercidas na superfície do solo pelas máquinas e implementos (Kamimura et al., 2009). Solos com plantio direto têm apresentado problemas de compactação subsuperficial (Reinert et al., 2008).

Um dos problemas do SPD é a dificuldade dos produtores em adaptar corretamente as semeadoras-adubadoras para realizarem a semeadura, ocasionando, muitas vezes, imprevistos como a distribuição superficial do fertilizante no solo em mistura com as sementes (Arf et al., 2008). Segundo Silva et al. (2008), a profundidade de deposição das sementes pode afetar sua germinação, condicionada pela temperatura, pelo teor de água, pelas peculiaridades da semente, propriedades físicas e químicas do solo, pelo clima e manejo da cultura, dentre outros fatores.

Para que isso não ocorra é necessário que a semeadora-adubadora tenha mecanismos eficientes de corte dos restos culturais e distribuição do fertilizante que proporcione sua colocação em profundidade adequada (Arf $e t$ al., 2008). Portanto, a semeadora é o equipamento mais importante para o sucesso do SPD. Além da distribuição uniforme e da colocação adequada para garantir a germinação, a semeadora no SPD desempenha a função de abertura do sulco e descompactação do solo, fazendo o corte da palha e o rompimento do solo na linha de semeadura (Santos et al., 2008).

Mecanismos de abertura de sulcos, inoculação e adubação nitrogenada em feijoeiro em sistema plantio direto foram estudados por Kaneko et al. (2010), e verificaram que o mecanismo de abertura de sulco para a distribuição de fertilizantes do tipo haste escarificadora proporcionou maior população final de plantas, quando comparado ao uso do disco duplo desencontrado, podendo com isso favorecer o aumento da produtividade de grãos.

Trogello et al. (2012), trabalhando com diferentes tipos de abertura de sulcos (disco duplo e haste escarificadora) em Latossolo Vermelho Argiloso, verificaram que a haste obteve maiores produções de milho quando comparada com o disco duplo. Quando avaliado o estande das plantas, não foi verificada nenhuma diferença estatística para os dois diferentes mecanismos sulcadores (disco e haste).

Nascente et al. (2011), estudando a produtividade do arroz em SPD e cultivo convencional, em razão do manejo do solo e da adubação, verificaram que as semeadoras para sistema plantio direto, equipadas com dispositivos para abertura de sulcos (haste escarificadora), mostraram resultados positivos na indução do aprofundamento do sistema radicular do arroz de terras altas.

Cultivares de terras altas possuem características de sistema radicular profundo e alta relação raiz/parte aérea, conferindo resistência à seca e maior rusticidade às plantas, porém com baixo potencial produtivo em relação às cultivares dos ecossistemas de várzea (Matsuo \& Mochizuki, 2009).

A adubação nitrogenada está intimamente relacionada à produtividade e melhoria da qualidade nutricional do grão do arroz. Entretanto, quando em excesso, o nitrogênio pode proporcionar aumento na altura da planta, predispondo-a ao acamamento. Mingotte et al. (2012), estudando o manejo da adubação nitrogenada, verificaram que, com o aumento das doses de $\mathrm{N}$, houve um incremento na altura de planta, no número de colmos e de panículas $/ \mathrm{m}^{2}$, no número total de espiguetas e na produtividade de grãos, nas áreas com irrigação. Contudo, nas áreas de sequeiro, a produtividade de grãos de arroz foi reduzida.

Segundo a Embrapa (2009), recomenda-se uma aplicação na base (10-30 $\mathrm{kg} \mathrm{ha}^{-1}$ ), por ocasião da semeadura, e uma (20-70 $\left.\mathrm{kg} \mathrm{ha}^{-1}\right)$ em cobertura, no perfilhamento das plantas, pois o arroz absorve $\mathrm{N}$ em todo o seu ciclo, mas as fases do perfilhamento e o início do primórdio floral são considerados críticos.

Nascente et al. (2011) verificaram diferenças na produtividade do arroz em SPD e convencional e nas épocas de aplicação do $\mathrm{N}$, pois quando aplicado todo na semeadura e com o uso do escarificador a produtividade foi maior. O mecanismo aumenta a abertura do sulco (haste escarificadora) e a disponibilidade de nitrogênio para as plantas, devido à maior mobilização do solo. Nesse caso, o teor de $\mathrm{N}$ disponível é aumentado devido à maior mineralização da matéria orgânica e nitrificação causada por melhor aeração.

O objetivo deste trabalho foi avaliar a influência dos mecanismos de abertura do sulco para deposição de fertilizantes na semeadura e da adubação nitrogenada em cobertura no crescimento e na produtividade do arroz de terras altas em SPD.

\section{MATERIAL E MÉTODOS}

Este trabalho foi realizado no município de Selvíria, Mato Grosso do Sul, a 51 $22^{\prime}$ de longitude Oeste de Greenwich e $20^{\circ} 22^{\prime}$ de latitude Sul, com altitude de $335 \mathrm{~m}$, nos anos agrícolas 2003/04 e 2004/05. O solo do local é do tipo Latossolo Vermelho epi-eutrófico, textura argilosa (Demattê, 1980; Embrapa, 2006). A precipitação pluvial, temperatura e umidade relativas médias anuais são de aproximadamente $1.370 \mathrm{~mm}, 23,5^{\circ} \mathrm{C}$ e 70 a $80 \%$, respectivamente. 
Antes da instalação do experimento foi coletada amostra composta originada da coleta de 20 amostras simples de solo coletadas em toda área experimental ao acaso, na camada de 0,00 a 0,20 m. A análise da fertilidade do solo, segundo metodologia descrita em Raij \& Quaggio (1983), revelou os seguintes valores: M.O. $=27 \mathrm{~g} \mathrm{dm}^{-3} ; \mathrm{P}_{\text {resina }}=19$ $\mathrm{mg} \mathrm{dm}{ }^{-3} ; \mathrm{pH}\left(\mathrm{CaCl}_{2}\right)=4,7 ; \mathrm{K}^{+}, \mathrm{Ca}^{+2}, \mathrm{Mg}^{+2}, \mathrm{H}+\mathrm{Al} \mathrm{e} \mathrm{CTC}=$ 2,$8 ; 25 ; 16 ;$ e $43 ; 86,8 \mathrm{mmol}_{\mathrm{c}} \mathrm{dm}^{-3}$, respectivamente, e $\mathrm{V}=$ $51 \%$.

Nos dois anos anteriores à realização do experimento (2002 e 2003), foram cultivados feijão e milheto na área experimental, com a finalidade de formar cobertura morta necessária para o sistema de plantio direto.

O delineamento experimental foi em blocos casualizados, dispostos em um esquema fatorial 2 x 6 . Os tratamentos foram constituídos pela combinação de dois mecanismos de distribuição do fertilizante na semeadura (disco duplo e haste escarificadora) e doses de nitrogênio em cobertura $\left(0,25,50,75,100\right.$ e $\left.125 \mathrm{~kg} \mathrm{ha}^{-1}\right)$, em sistema de plantio direto, com quatro repetições.

As doses de $\mathrm{N}$ em cobertura foram propostas levando em consideração a recomendação de Cantarella et al. (1997) para cultura do arroz de terras altas irrigado por aspersão, no Estado de São Paulo. As parcelas foram constituídas por seis linhas de 5,0 $\mathrm{m}$ de comprimento, espaçadas 0,35 $\mathrm{m}$ entre si. A área útil foi constituída por quatro linhas centrais, desprezando $0,50 \mathrm{~m}$ em ambas as extremidades de cada linha.

A adubação básica nos sulcos de semeadura foi calculada de acordo com as características químicas do solo e levando-se em consideração as recomendações de Cantarella et al. (1997) e foi constituída de $200 \mathrm{~kg} \mathrm{ha}^{-1} \mathrm{da}$ formulação 08-28-16.

A semeadura foi realizada mecanicamente em 12 de novembro de 2003 e 22 de novembro de 2004, utilizandose o cultivar IAC 202, que apresenta arquitetura moderna com folhas eretas e porte baixo (média $87 \mathrm{~cm}$ ), resistência ao acamamento, com ciclo médio de 120 a 128 dias e floração até 87 dias; as panículas são em média de 20 cm de comprimento com 169 grãos por panícula, apresentam baixa incidência de manchas foliares em condições normais de cultivo e moderada suscetibilidade à brusone, sendo o rendimento de grãos inteiros em média de $62 \%$ no beneficiamento, com grãos do tipo longos, finos e translúcidos, sendo o mesmo cultivado especialmente com irrigação suplementar (IAC, 2013). Foi utilizado um número de sementes certificadas, necessário para obter um estande de 120 plantas $/ \mathrm{m}^{2}$. O tratamento de sementes foi realizado com thiodicarb + óxido de zinco $(0,600 \mathrm{~kg}+0,500$ $\mathrm{kg}$ do i.a. por $100 \mathrm{~kg}$ de sementes). Em ambos os anos, a adubação nitrogenada em cobertura foi realizada 30 dias após a emergência (DAE) das plântulas, utilizando como fonte a ureia.
O fornecimento de água foi efetuado de três em três dias, ou quando necessário, por aspersão, por meio de um sistema fixo de irrigação do tipo pivô central. O volume de rega da irrigação foi de $14 \mathrm{~mm}$. O controle de plantas daninhas foi realizado com a utilização de herbicidas específicos. No caso do plantio direto, a dessecação da cobertura do solo foi realizada com glyphosate $(1,56 \mathrm{~kg}$ $\mathrm{ha}^{-1}$ do i.a.). Como na área de cultivo tem ocorrido com frequência capim colchão (Digitaria sanguinalis), capimcarrapicho (Cenchrus echinatus) e capim marmelada (Brachiaria plantaginea), foi aplicado logo após a semeadura o herbicida oxadiazon (1,00 $\mathrm{kg} \mathrm{ha}^{-1}$ do i.a.) nos dois anos de cultivo. As demais plantas daninhas não controladas pelos herbicidas o foram manualmente com auxílio de enxada.

Durante o crescimento e após a colheita da cultura do arroz de terras altas foram avaliadas a emergência de plântulas e floração. Para emergência foi determinado o número de dias transcorridos entre a semeadura e a emergência da maioria das plântulas (caracterizado como ponto de agulhamento), por avaliação visual em campo. Já na floração foi avaliado o número de dias transcorridos entre a emergência e a floração de $50 \%$ das plantas das parcelas, por avaliação visual em campo.

Para determinação do teor de $\mathrm{N}$ nas folhas, por ocasião do florescimento, foram coletados os limbos foliares de 30 folhas bandeira por parcela, conforme proposto por Cantarella et al. (1997), que após a secagem foram moídas para, em seguida, passarem por digestão sulfúrica, conforme metodologia de Sarruge \& Haag (1974).

A altura de plantas foi determinada em 10 plantas ao acaso, na área útil de cada parcela, durante o estádio de grãos na forma pastosa, sendo a distância compreendida desde a superfície do solo até a extremidade superior da panícula mais alta. O número de panículas $/ \mathrm{m}^{2}$ foi determinado por meio de contagem do número de panículas em 1,0 m de fileira de plantas na área útil das parcelas e posteriormente calculado por metro quadrado. $\mathrm{O}$ número de grãos cheios foi determinado pela contagem do número de grãos cheios de 20 panículas, após o desprendimento dos grãos manualmente da panícula e, em seguida, separação deles por meio de fluxo de ar ou "soprador" e posterior contagem em um contador de grãos. A massa de 100 grãos foi avaliada via coleta ao acaso e pesagem de duas amostras de 100 grãos de cada parcela (13\% base úmida).

A produtividade de grãos foi avaliada por ocasião da colheita de três linhas centrais provenientes da área útil das parcelas e determinada a pesagem dos grãos em casca, corrigindo-se a umidade para $13 \%$ e convertendo em $\mathrm{kg} \mathrm{ha}^{-1}$. Para o rendimento de engenho foi coletada uma amostra de $100 \mathrm{~g}$ de grãos de arroz em casca de cada parcela, a qual foi processada em engenho de prova, por 1 minuto; em seguida, os grãos brunidos (polidos) foram 
pesados e o valor encontrado foi considerado como rendimento de benefício, sendo os resultados expressos em porcentagem. Posteriormente, os grãos brunidos foram colocados no "Trieur" n 2 e sua separação foi processados por 30 segundos. Os grãos que permaneceram no "Trieur" foram pesados, obtendo-se o rendimento de inteiros e dos demais, grãos quebrados, ambos expressos em porcentagem.

Os efeitos dos mecanismos de abertura dos sulcos sobre as variáveis analisadas foram interpretados por meio da análise de variância, segundo um delineamento de blocos casualizados. A diferença entre as médias dos tratamentos foi avaliada pelo teste de Tukey, considerando significância de 5\%. Com a finalidade de ajustar as curvas das variáveis respostas nas diferentes doses, foi realizada a análise de regressão. Os modelos foram escolhidos com base na significância dos coeficientes de regressão e no coeficiente de determinação, utilizando-se o Sistema de Análise Estatística para Microcomputadores - SANEST (Zonta \& Machado, 1986).

\section{RESULTADOS E DISCUSSÃO}

A emergência do arroz ocorreu uniformemente nos dois anos, aproximadamente entre o quinto e sexto dias após a semeadura. O florescimento pleno ocorreu aproximadamente aos 91 e 82 DAE e a colheita foi realizada, manualmente, aos 113 e 103 dias após a emergência das plantas, respectivamente para os anos agrícolas 2003/04 e 2004/ 05. Durante o período de cultivo, nos dois anos agrícolas, não houve problema com acamamento de plantas. O cultivar utilizado, IAC 202, é do tipo moderno, e de acordo com Diniz (1975), plantas com esse tipo de crescimento (determinado, de arquitetura moderna com folhas eretas e porte baixo) não apresentam acamamento, mesmo com altos níveis de adubação nitrogenada. Também Silva et al. (2009), estudando algumas características das variedades de arroz de terras altas, verificaram resistência ao acamamento da variedade estudada, florescimento pleno em 89 dias e a colheita após 120 dias em região do cerrado.

Verificou-se efeito dos mecanismos de distribuição do fertilizante e das doses de nitrogênio aplicadas em cobertura na altura de plantas e teor de $\mathrm{N}$ nas folhas (Tabela 1). Pode-se observar que o uso da haste escarificadora como mecanismo de abertura do sulco para distribuição do fertilizante propiciou maior altura de plantas nos dois anos de cultivo e maior teor de $\mathrm{N}$ nas folhas em 2003/04. Isso ocorreu porque esse mecanismo proporcionou melhores condições físicas do solo para o enraizamento das plantas em relação ao disco duplo para a abertura do sulco de distribuição do fertilizante, explorando, assim, maior volume de solo para retirada de água e de nutrientes. $\mathrm{Na}$ literatura vários trabalhos (Beutler et al., 2006; Kaneko et al., 2010; Nascente et al., 2011; Fonseca et al., 2012) deram ênfase à profundidade de semeadura e a compactação do solo sobre as sementes, alertando cada vez mais da importância das operações de semeadura. Segundo Seki et al. (2012), o uso do facão não interferiu na produtividade do milho, mas permitiu boa mobilização do solo na linha de semeadura, em sistema plantio direto.

Quanto à aplicação de nitrogênio em cobertura, houve aumento na altura de plantas, e os dados ajustaram-se às equações lineares crescentes nos dois anos de cultivo (Tabela 1), porém vale ressaltar que a partir da dose $50 \mathrm{~kg}$ $\mathrm{ha}^{-1}$ de $\mathrm{N}$ ocorre certa estabilização na altura de planta, caracterizando consumo de luxo de $\mathrm{N}$, e que o excesso desse nutriente pode causar o acamamento em alguns cultivares de arroz. Isso porque o $\mathrm{N}$ faz parte da molécula de clorofila, proporcionando, assim, aumento na produção de fotoassimilados e, portanto, maior altura de plantas. Fato esse comprovado por Fageria \& Stone (2003), que ainda complementaram afirmando que o $\mathrm{N}$ é componente da clorofila com expressiva participação no aumento da área foliar da planta, a qual aumenta a eficiência na interceptação da radiação solar e da taxa fotossintética e, consequentemente, no crescimento e na produtividade de grãos. Resultados semelhantes foram observados por Fonseca et al. (2012) para o IAC 202 nas mesmas condições edafoclimáticas e doses de $\mathrm{N}$ testadas no presente trabalho e por Fidelis et al. (2012) com arroz de terras altas cultivado em condições de baixa e alta disponibilidades de N, em Gurupi, Tocantins.

Para o teor foliar de N, em 2003/04 os dados ajustaramse às equações lineares crescentes, e em 2004/05 houve efeito da interação mecanismos $\mathrm{x}$ doses de N, e o desdobramento está apresentado na Tabela 2. Observa-se que no desdobramento mecanismos de abertura do sulco para deposição do fertilizante dentro de doses de N, o escarificador apresentou menores teores de $\mathrm{N}$ nas folhas até a dose de $75 \mathrm{~kg} \mathrm{ha}^{-1}$ de $\mathrm{N}$ e não diferiu do disco duplo nas outras duas doses. Já para doses dentro de mecanismos de abertura do sulco os dados ajustaram-se às equações lineares crescentes para escarificador e disco duplo em 2004/05. Fonseca et al. (2012), avaliando o teor de N nas folhas bandeira do arroz de terras altas irrigado por aspersão, em razão do preparo do solo (grade aradora + grade niveladora, escarificador + grade niveladora e plantio direto) e de doses de $\mathrm{N}$ em cobertura, constataram efeito significativo apenas para doses de até $94 \mathrm{~kg} \mathrm{ha}^{-1} \mathrm{de}$ N.

Vale ressaltar que os teores de $\mathrm{N}$ foliar obtidos para o mecanismo escarificador ficaram abaixo da faixa adequa-

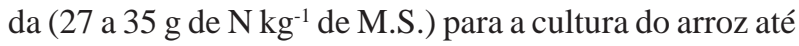
a dose de $75 \mathrm{~kg} \mathrm{ha}^{-1}$ de $\mathrm{N}$, e para o disco duplo somente nas doses de 0 e $25 \mathrm{~kg} \mathrm{ha}^{-1}$ os teores foram menores que os considerados adequados por Cantarella et al. (1997). 
Com relação ao número de panículas por metro quadrado (Tabela 1), houve efeito dos mecanismos de distribuição do fertilizante em 2003/04, e os valores foram maiores com a utilização do disco duplo. Já em 2004/05 houve efeito da interação mecanismos de aplicação de fertilizante $\mathrm{x}$ doses de $\mathrm{N}$ em cobertura, e o desdobramento está apresentado na Tabela 3 , em que se verificou que para mecanismos dentro de doses houve diferenças entre os tratamentos apenas nas doses de 50, 100 e $125 \mathrm{~kg} \mathrm{ha}^{-1}$. O tratamento com disco duplo apresentou maior número de panículas $/ \mathrm{m}^{2}$ nas doses de 50 e $125 \mathrm{~kg} \mathrm{ha}^{-1}$ e menor número na dose de $100 \mathrm{~kg} \mathrm{ha}^{-1}$, no ano de 2004/05. Quanto ao desdobramento de doses dentro de mecanismos de aplicação do fertilizante, os dados não se ajustaram às equações lineares ou quadráticas. A aplicação de $\mathrm{N}$ em cobertura não interferiu nessa característica da cultura do arroz nos dois anos de cultivo. É interessante ressaltar que por ocasião da semeadura foram utilizados $16 \mathrm{~kg} \mathrm{ha}^{-1} \mathrm{de} \mathrm{N}$, e a cultura antecessora ao arroz foi uma leguminosa (cultura do feijão), o que pode ter contribuído para bom perfilhamento das plantas, mesmo no tratamento que não recebeu adubação nitrogenada em cobertura.

Por outro lado, Fonseca et al. (2012) verificaram que o número de panículas $/ \mathrm{m}^{2}$ do IAC 202 aumentou linearmen-

Tabela 1. Valores médios de alturas de plantas, teor de nitrogênio foliar e $\mathrm{n}^{\mathrm{o}}$ de panículas $/ \mathrm{m}^{2}$ (maturação), obtidos para a cultura do

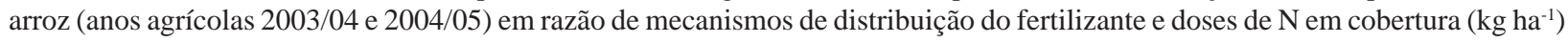

\begin{tabular}{|c|c|c|c|c|c|c|}
\hline \multirow{2}{*}{ Tratamentos } & \multicolumn{2}{|c|}{ Altura de plantas $(\mathrm{cm})$} & \multicolumn{2}{|c|}{ Teor de N $\left(\mathrm{g} \mathrm{kg}^{-1}\right)$} & \multicolumn{2}{|c|}{$\mathrm{N}^{0}$ de panículas $/ \mathrm{m}^{2}$} \\
\hline & $2003 / 04$ & $2004 / 05$ & $2003 / 04$ & $2004 / 05$ & $2003 / 04$ & $2004 / 05$ \\
\hline \multicolumn{7}{|c|}{ Mecanismos de distribuição } \\
\hline Disco duplo & $94,4 \mathrm{~b}$ & $94,1 \mathrm{~b}$ & $25,71 \mathrm{~b}$ & 27,58 & $232 \mathrm{a}$ & 244 \\
\hline Escarificador & $97,6 \mathrm{a}$ & $109,3 \mathrm{a}$ & $27,29 \mathrm{a}$ & 26,26 & $213 b$ & 271 \\
\hline \multicolumn{7}{|l|}{ Doses de $\mathbf{N}$} \\
\hline 0 & $90,2^{(1)}$ & $100,6^{(2)}$ & $23,70^{(3)}$ & 24,63 & 219 & 278 \\
\hline 25 & 91,9 & 99,0 & 24,73 & 24,43 & 205 & 272 \\
\hline 50 & 97,3 & 102,0 & 26,04 & 27,32 & 232 & 273 \\
\hline 75 & 97,3 & 101,4 & 26,98 & 27,30 & 207 & 146 \\
\hline 100 & 97,5 & 103,5 & 27,79 & 28,57 & 240 & 290 \\
\hline 125 & 100,4 & 103,9 & 29,75 & 29,28 & 230 & 277 \\
\hline$\overline{\mathrm{CV}}(\%)$ & 4,88 & 4,07 & 8,17 & 3,66 & 13,64 & 7,59 \\
\hline
\end{tabular}

Médias seguidas de mesma letra, dentro do parâmetro (Mecanismos de aplicação), não diferem estatisticamente entre si pelo teste de Tukey a $5 \%$.

${ }^{(1)} \mathrm{y}=91,1068+0,0783 \mathrm{x}\left(\mathrm{R}^{2}=0,84\right) ;{ }^{(2)} \mathrm{y}=99,6488+0,0333 \mathrm{x}\left(\mathrm{R}^{2}=0,74\right) ; \mathrm{e}^{(3)} \mathrm{y}=23,615+0,0461 \mathrm{x}\left(\mathrm{R}^{2}=0,98\right)$

Tabela 2. Desdobramento da interação significativa da análise de variância referente ao teor de N nas folhas do arroz (ano agrícola 2004/05)

\begin{tabular}{|c|c|c|c|c|c|c|c|}
\hline \multirow{3}{*}{ Mecanismos } & \multicolumn{7}{|c|}{ Doses de $\mathbf{N}$ em cobertura } \\
\hline & $\mathbf{0}$ & 25 & 50 & 75 & 100 & 125 & \\
\hline & \multicolumn{7}{|c|}{$\mathrm{g} \mathrm{kg}^{-1}$} \\
\hline Disco duplo & 25,76 a & $25,85 \mathrm{a}$ & $28,67 \mathrm{a}$ & $28,07 \mathrm{a}$ & 28,93 & 29,72 & $\mathrm{RL} * *(1)$ \\
\hline Escarificador & $23,49 \mathrm{~b}$ & $23,00 \mathrm{~b}$ & $25,97 \mathrm{~b}$ & $26,53 \mathrm{~b}$ & 28,21 & 28,84 & $\mathrm{RL} * *(2)$ \\
\hline DMS & \multicolumn{7}{|c|}{ Mecanismos dentro de doses de $\mathrm{N}-1,41$} \\
\hline
\end{tabular}

Médias seguidas de mesma letra, minúscula nas colunas, não diferem estatisticamente entre si pelo teste de Tukey a 5\%. RL = Regressão linear e RQ = Regressão Quadrática.

(1) $\mathrm{y}=25,6565+0,0307 \mathrm{x}\left(\mathrm{R}^{2}=0,84\right) \mathrm{e}^{(2)} \mathrm{y}=23,0907+0,0507 \mathrm{x}\left(\mathrm{R}^{2}=0,92\right)$

Tabela 3. Desdobramento da interação significativa da análise de variância referente ao número de panícula/m² do arroz (ano agrícola 2004/05)

\begin{tabular}{lcccccc}
\hline & \multicolumn{6}{c}{ Doses de N em cobertura } \\
\cline { 2 - 6 } Mecanismos & $\mathbf{0}$ & $\mathbf{2 5}$ & $\mathbf{5 0}$ & $\mathbf{7 5}$ & $\mathbf{1 0 0}$ & $\mathbf{1 2 5}$ \\
\hline Disco duplo & 273 & 260 & $293 \mathrm{a}$ & 245 & $275 \mathrm{~b}$ & $299 \mathrm{a}$ \\
Escarificador & 282 & 285 & $253 \mathrm{~b}$ & 247 & $307 \mathrm{a}$ & $254 \mathrm{~b}$ \\
DMS & Mecanismos dentro de doses de N - 29,85 & & n.s. & \\
\hline
\end{tabular}

Médias seguidas de mesma letra, minúscula nas colunas, não diferem estatisticamente entre si pelo teste de Tukey a 5\%. n.s. = não significativo.

Rev. Ceres, Viçosa, v. 60, n.6, p. 802-810, nov/dez, 2013 
te com o incremento dessas mesmas doses de N. Fageria et al. (2011) também obtiveram aumento no número de perfilhos de arroz de terras altas com a adubação nitrogenada tanto em cultivo de sequeiro quanto irrigado por aspersão. O perfilhamento está intimamente ligado à quantidade de $\mathrm{N}$ disponível às plantas, comportamento esse verificado por Medeiros et al. (2005).

Os resultados referentes ao número de grãos cheios estão apresentados na Tabela 4. Houve efeito dos mecanismos de distribuição do fertilizante, em que o uso da haste escarificadora apresentou maiores valores para o componente avaliado nos dois anos de cultivo. A aplicação de $\mathrm{N}$ em cobertura influenciou positivamente o número de grãos cheios/panícula, e os dados se ajustaram às funções lineares crescentes em 2003/04 e 2004/05. Resultados discordantes foram encontrados por Cazetta et al. (2006), que estudando diferentes tipos de plantas de cobertura e doses de $\mathrm{N}$, verificaram que os tratamentos não influenciaram alguns parâmetros avaliados (grãos inteiros, grãos quebrados, rendimento de engenho), provavelmente em razão da imobilização do N pelos microrganismos decompositores, uma vez que o SPD ainda estava em fase inicial.

Quanto à massa de 100 grãos (Tabela 4), constatou-se que nos dois anos de cultivo os mecanismos de distribuição do fertilizante não interferiram nos valores obtidos. Por outro lado, no primeiro ano de cultivo a adubação nitrogenada em cobertura propiciou redução na massa de 100 grãos e os dados se ajustaram a uma equação linear, ou seja, houve redução na massa de grãos com o aumento das doses de nitrogênio aplicadas em cobertura. Vale ressaltar que a adubação nitrogenada propiciou aumento no número de grãos cheios e essa deve ter sido a razão para o comportamento obtido com a massa de 100 grãos. Os cultivares de arroz de terras altas geralmente possuem maior massa unitária de grãos do que os de arroz inundado, e essa característica é influenciada pela quantidade de nitrogênio disponivel (Guimarães et al., 2002).

No segundo ano de cultivo houve interação significativa de mecanismos de aplicação $\mathrm{x}$ adubação nitrogenada em cobertura, e o desdobramento consta na Tabela 5. Para mecanismos de aplicação do fertilizante dentro de doses de $\mathrm{N}$, o escarificador apresentou maior massa de 100 grãos nas doses 0,25 e $75 \mathrm{~kg} \mathrm{ha}^{-1}$ de $\mathrm{N}$, mas nas demais não houve diferença entre os dois mecanismos. Quanto ao desdobramento doses de N em cobertura dentro de mecanismos de distribuição de fertilizante, para o escarificador os dados se ajustaram a uma função linear decrescente, ou seja, houve redução na massa de 100 grãos com o aumento nas doses de N. Vale ressaltar que houve aumento no número de grãos cheios em razão das doses de $\mathrm{N}$, propiciando assim maior dificuldade para um bom enchimento de grãos nas maiores doses de $\mathrm{N}$ utilizadas. Na literatura, vários autores têm constatado que a massa de 100 grãos é pouco influenciada pelo fornecimento de N (Farinelli et al. 2004; Fidelis et al. 2012; Fonseca et al., 2012). Por outro lado, Artigiani et al. (2012) relataram que houve redução na massa de 100 grãos de arroz de terras altas com o aumento das doses de N.

Em relação à produtividade de grãos (Tabela 4), verificou-se que não houve diferenças entre os mecanismos de abertura dos sulcos para deposição do fertilizante, embora salienta-se que a produtividade da cultura tenha sido promissora nos dois anos de cultivo. Contudo, o aumento nas doses de $\mathrm{N}$ em cobertura proporcionou aumento na produtividade de grãos, no primeiro, até a dose de 75 $\mathrm{kg} \mathrm{ha}^{-1}$ e os dados se ajustaram à função quadrática em

Tabela 4. Valores médios de grãos cheios, massa de 100 grãos e produtividade de grãos, obtidos para a cultura do arroz (anos agrícolas 2003/04 e 2004/05) em razão de mecanismos de distribuição do fertilizante e doses de N em cobertura (kg ha-1)

\begin{tabular}{|c|c|c|c|c|c|c|}
\hline \multirow{2}{*}{ Tratamentos } & \multicolumn{2}{|c|}{ Grãos cheios } & \multicolumn{2}{|c|}{ Massa de 100 grãos (g) } & \multicolumn{2}{|c|}{ Produtividade (kg ha-1) } \\
\hline & $2003 / 04$ & $2004 / 05$ & 2003/04 & $2004 / 05$ & 2003/04 & $2004 / 05$ \\
\hline \multicolumn{7}{|c|}{ Mecanismos de distribuição } \\
\hline Disco duplo & $139,13 \mathrm{~b}$ & $155,78 \mathrm{~b}$ & 2,13 & 2,28 & 3.099 & 3.900 \\
\hline Escarificador & $149,32 \mathrm{a}$ & 176,46 a & 2,15 & 2,45 & 3.020 & 4.168 \\
\hline \multicolumn{7}{|l|}{ Doses de N } \\
\hline 0 & $130,82^{(1)}$ & $162,95^{(2)}$ & $2,18^{(3)}$ & 2,47 & $2.633^{(4)}$ & 4.134 \\
\hline 25 & 142,85 & 156,59 & 2,16 & 2,29 & 3.008 & 3.919 \\
\hline 50 & 137,97 & 152,54 & 2,13 & 2,38 & 3.248 & 4.007 \\
\hline 75 & 152,87 & 164,28 & 2,19 & 2,44 & 3.445 & 3.958 \\
\hline 100 & 156,49 & 183,73 & 2,12 & 2,28 & 3.172 & 4.311 \\
\hline 125 & 144,37 & 176,63 & 2,04 & 2,31 & 2.855 & 3.873 \\
\hline $\mathrm{CV}(\%)$ & 9,62 & 11,49 & 4,36 & 10,01 & 19,95 & 13,05 \\
\hline
\end{tabular}

Médias seguidas de mesma letra, dentro do parâmetro (Mecanismos de aplicação), não diferem estatisticamente entre si pelo teste de Tukey a $5 \%$.

${ }^{(1)} \mathrm{y}=135,4002+0,1412 \mathrm{x}\left(\mathrm{R}^{2}=0,49\right) ;{ }^{(2)} \mathrm{y}=154,5852+0,1846 \mathrm{x}\left(\mathrm{R}^{2}=0,53\right) ;{ }^{(3)} \mathrm{y}=2,1906-0,0009 x\left(\mathrm{R}^{2}=0,55\right) ; e^{(4)} \mathrm{y}=2603,7169+21,7432 \mathrm{x}-$ $0,1575 \mathrm{x}^{2}\left(\mathrm{R}^{2}=0,96\right)$ 
2003/04, comportamento semelhante foi encontrado por Farinelli et al. (2004). A aplicação de $69 \mathrm{~kg} \mathrm{ha}^{-1} \mathrm{de} \mathrm{N} \mathrm{em}$ cobertura, de acordo com a produtividade máxima ajustada à função quadrática, propiciou um acréscimo de 28,0\% em 2003/04 na produtividade da cultura em relação ao tratamento testemunha (sem $\mathrm{N}$ em cobertura). A redução na produtividade da cultura nas doses mais elevadas, principalmente $125 \mathrm{~kg} \mathrm{ha}^{-1}$, pode estar relacionada com a incidência de brusone. Segundo Prabhu et al. (2002), a aplicação da totalidade de $\mathrm{N}$ no sulco, pela ocasião da semeadura, aumenta significativamente a severidade da brusone, quando comparada com a aplicação parcelada. Fageria et al. (2003), estudando o comportamento do N, verificaram que com um controle apropriado da brusone $\mathrm{o}$ $\mathrm{N}$ aumenta a produtividade de grãos do arroz irrigado e seu manejo adequado é fundamental para redução do custo da produção da cultura e da poluição ambiental.

O rendimento de benefício, inteiros e quebrados (Tabela 6) não foi influenciado pelos mecanismos de abertura do sulco para deposição do fertilizante no primeiro ano de cultivo, concordando com os resultados encontrados por Bastos (2000), Arf et al. (2002) e Cazetta et al. (2006). Já no segundo ano (2004/05) houve efeito significativo, e o uso da haste propiciou maior rendimento de benefício de inteiros e menor quantidade de grãos quebrados. Para a adubação nitrogenada em cobertura verificou-se que o rendimento de benefício ajustou-se a uma função linear crescente. Bordin et al. (2003), testando doses de N (0, 25, $50 \mathrm{e} 75 \mathrm{~kg} \mathrm{ha}^{-1}$ ), também observaram ajuste à função linear crescente para tal parâmetro. Por outro lado, Artigiani et al. (2012) não verificaram efeito das doses de $\mathrm{N}$ sobre o rendimento de benefício de arroz de terras altas em condições irrigadas.

No que se refere ao rendimento de inteiros, os dados ajustaram-se às funções lineares e quadráticas. No caso da avaliação de grãos quebrados, em 2003/04 houve ajuste à função quadrática. Já em 2004/05, os dados ajustaram-se à função linear decrescente, concordando com Cazetta et al. (2006). Entretanto, do ponto de vista prático, as diferenças são pequenas, e todos os tratamentos

Tabela 5. Desdobramento da interação significativa da análise de variância referente a massa de 100 grãos do arroz (ano agrícola 2004/05)

\begin{tabular}{|c|c|c|c|c|c|c|c|}
\hline \multirow{3}{*}{ Mecanismos } & \multicolumn{7}{|c|}{ Doses de $\mathbf{N}$ em cobertura } \\
\hline & $\mathbf{0}$ & 25 & 50 & 75 & 100 & 125 & \\
\hline & \multicolumn{7}{|c|}{$\mathbf{g}$} \\
\hline Disco duplo & $2,29 \mathrm{~b}$ & $2,11 b$ & 2,42 & $2,25 \mathrm{~b}$ & 2,15 & 2,44 & n.s. \\
\hline Escarificador & $2,65 \mathrm{a}$ & $2,47 \mathrm{a}$ & 2,33 & $2,63 \mathrm{a}$ & 2,41 & 2,19 & R.L.*.(1) \\
\hline DMS & \multicolumn{7}{|c|}{ Mecanismos dentro de doses de $\mathrm{N}-0,34$} \\
\hline
\end{tabular}

Médias seguidas de mesma letra, minúscula nas colunas, não diferem estatisticamente entre si pelo teste de Tukey a 5\%. n.s. = não significativo e R.L. = Regressão linear.

${ }^{(1)} \mathrm{y}=2,6017-0,0025 \mathrm{x}\left(\mathrm{R}^{2}=0,43\right)$

Tabela 6. Valores médios de rendimento de benefício, rendimento de inteiros e grãos quebrados, obtidos para a cultura do arroz (anos agrícolas 2003/04 e 2004/05) em razão de mecanismos de distribuição do fertilizante e doses de N em cobertura (kg ha-1)

\begin{tabular}{|c|c|c|c|c|c|c|}
\hline \multirow{3}{*}{ Tratamentos } & \multicolumn{2}{|c|}{ Rendimento de benefício } & \multicolumn{2}{|c|}{ Rendimento de inteiros } & \multicolumn{2}{|c|}{ Grãos quebrados } \\
\hline & $2003 / 04$ & $2004 / 05$ & $2003 / 04$ & $2004 / 05$ & $2003 / 04$ & $2004 / 05$ \\
\hline & \multicolumn{6}{|c|}{$\%$} \\
\hline \multicolumn{7}{|c|}{ Mecanismos de distribuição } \\
\hline Disco duplo & 72,19 & $69,80 \mathrm{~b}$ & 57,56 & $60,15 b$ & 14,52 & $9,71 \mathrm{a}$ \\
\hline Escarificador & 71,64 & $71,55 \mathrm{a}$ & 56,97 & $63,94 \mathrm{a}$ & 14,54 & $7,63 \mathrm{~b}$ \\
\hline \multicolumn{7}{|l|}{ Doses de $\mathbf{N}$} \\
\hline 0 & 73,03 & $69,62^{(1)}$ & $57,88^{(2)}$ & $59,89^{(3)}$ & $15,00^{(4)}$ & $9,72^{(5)}$ \\
\hline 25 & 71,93 & 69,85 & 57,89 & 60,32 & 13,91 & 9,60 \\
\hline 50 & 71,73 & 70,84 & 57,93 & 62,69 & 13,90 & 8,05 \\
\hline 75 & 72,20 & 70,36 & 59,46 & 61,75 & 12,98 & 8,85 \\
\hline 100 & 71,96 & 72,10 & 56,34 & 64,34 & 15,23 & 7,72 \\
\hline 125 & 70,65 & 71,27 & 54,09 & 63,29 & 16,16 & 8,06 \\
\hline $\mathrm{CV}(\%)$ & 2,95 & 2,41 & 6,39 & 5,12 & 15,91 & 19,39 \\
\hline
\end{tabular}

Médias seguidas de mesma letra, dentro do parâmetro (mecanismos de aplicação), não diferem estatisticamente entre si pelo teste de Tukey a $5 \%$.

(1) $\mathrm{y}=69,0+0,017 \mathrm{x}\left(\mathrm{R}^{2}=0,70\right) ;{ }^{(2)} \mathrm{y}=57,4+0,06 \mathrm{x}-0,0007 \mathrm{x}^{2}\left(\mathrm{R}^{2}=0,81\right) ;{ }^{(3)} \mathrm{y}=60,0+0,032 \mathrm{x}\left(\mathrm{R}^{2}=0,76\right) ;(4) \mathrm{y}=15,04-0,05 \mathrm{x}+0,00054 \mathrm{x}^{2}$ $\left(\mathrm{R}^{2}=0,84\right) ; \mathrm{e}^{(5)} \mathrm{y}=9,6-0,015 \mathrm{x}\left(\mathrm{R}^{2}=0,67\right)$

Rev. Ceres, Viçosa, v. 60, n.6, p. 802-810, nov/dez, 2013 
apresentam rendimento de benefício superior a $69 \%$ e rendimento de grãos inteiros variando de 54 a $64 \%$, que são valores excelentes, concordando com Arf et al. (2002), que observaram rendimento de benefício superior a $65 \%$ na mesma região onde foi desenvolvida essa pesquisa.

\section{CONCLUSÕES}

Os mecanismos de distribuição do fertilizante não interferiram na produtividade de grãos do arroz de terras altas irrigado por aspersão. O mecanismo do tipo haste escarificadora proporcionou maior altura de plantas e maior número de grãos cheios nos dois anos de cultivo.

A aplicação de nitrogênio em cobertura interferiu em algumas características agronômicas na produtividade de grãos e nos componentes de rendimento de engenho do arroz.

$\mathrm{O}$ aumento nas doses de $\mathrm{N}$ em cobertura propiciou, em média, acréscimo de $28 \%$ na produtividade do arroz, comparado com a testemunha na dose de $69 \mathrm{~kg} \mathrm{ha}^{-1} \mathrm{de} \mathrm{N}$ no primeiro ano de cultivo.

\section{AGRADECIMENTOS}

À FAPESP e ao CNPq, pela concessão das bolsas de Iniciação Científica; e aos funcionários da Fazenda de Ensino, Pesquisa e Extensão (FEPE) da Faculdade de Engenharia de Ilha Solteira (FEIS/UNESP).

\section{REFERÊNCIAS}

Arf O, Rodrigues RAF, Sá ME, Crusciol CAC \& Pereira JCR (2002) Preparo do solo, irrigação por aspersão e rendimento de engenho do arroz de terras altas. Scientia Agrícola, 59:321-326.

Arf O, Afonso RJ, Romanini Junior A, Silva MG \& Buzetti S (2008) Mecanismo de abertura de sulco e adubação nitrogenada no cultivo do feijoeiro em sistema plantio direto. Bragantia, 67:499-506.

Artigiani ACCA, Crusciol CAC, Arf O, Alvarez RCF \& Nascente AS (2012) Produtividade e qualidade industrial do arroz de terras altas em função da disponibilidade hídrica e adubação. Pesquisa Agropecuária Tropical, 42:340-349.

Bastos CR (2000) IAC 202: arroz de alta produtividade e qualidade para cultura de sequeiro. O Agronômico, 52:24-25.

Beutler NA, Centurion JF, Centurion MAPC \& Silva AP (2006) Efeito da compactação na produtividade de cultivares de soja em Latossolo vermelho. Revista Brasileira de Ciência do Solo, 30:787-794.

Bordin L, Farinelli R, Penariol FG \& Fornasieri Filho D (2003) Sucessão de cultivo de feijão-arroz com doses de adubação nitrogenada após adubação verde, em semeadura direta. Bragantia, 62:417-428.

Cantarella H, Raij BV \& Camargo CEO (1997) Cereais. In: Raij BV, Cantarella H, Quaggio JÁ \& Furlani AMC (Eds.) Recomendações de adubação e calagem para o Estado de São Paulo. Campinas, IAC. p.45-71. (Boletim Técnico, 100).
Cazetta DA, Arf O, Buzetti S, Sá ME \& Rodrigues RAF (2006) Qualidade industrial do arroz de terras altas cultivado após diferentes coberturas vegetais e doses de nitrogênio em sistema de plantio direto. Científica, 34:155-161.

Demattê JLI (1980) Levantamento detalhado dos solos do Campus Experimental de Ilha Solteira (SP), Piracicaba, ESALQ/USP. $131 \mathrm{p}$.

Diniz JA (1975) Comportamento de cultivares de arroz, em terras altas, sob regime de irrigação por aspersão em diferentes níveis de adubação nitrogenada. Dissertação de Mestrado. Universidade Federal de Viçosa, Viçosa. 53p.

Embrapa - Empresa Brasileira de Pesquisa Agropecuária (2006) Centro Nacional de Pesquisa de Solos. Sistema Brasileiro de Classificação de Solos. Rio de Janeiro, 306p.

Embrapa - Empresa Brasileira de Pesquisa Agropecuária (2009) Informações técnicas sobre o arroz de terras altas: Estados de Mato Grosso e Rondônia - safras 2009/2010 e 2010/2011. Santo Antônio de Goiás, Embrapa Arroz e Feijão. (Documentos, 247).

Fageria NK \& Stone LF (2003) Manejo do nitrogênio. In: Fageria NK, Stone, LF \& Santos AB (Eds.) Manejo da fertilidade do solo para o arroz irrigado. Santo Antônio de Goiás, Embrapa Arroz e Feijão. p.51-94.

Fageria NK, Santos AB \& Stone LF (2003) Manejo de nitrogênio em arroz irrigado. Santo Antônio de Goiás, Embrapa Arroz e Feijão. 4p. (Circular Técnica, 58).

Fageria NK, Moreira A \& Coelho AM (2011) Yield and yield components of upland rice as influenced by nitrogen sources. Journal of Plant Nutrition, 34:361-370.

Farinelli R, Penariol FG, Fornasieri Filho D \& Bordin L (2004) Efeitos da adubação nitrogenada e potássica em características agronômicas de arroz de sequeiro cultivado sob plantio direto. Revista Brasileira de Ciência do Solo, 28:447-454.

Fidelis RR, Rodrigues AM, Silva GF, Barros HB, Pinto LC \& Aguiar RWS (2012) Eficiência do uso de nitrogênio em genótipos de arroz de terras altas. Pesquisa Agropecuária Tropical, 42:124128.

Fonseca AE, Arf O, Orioli Júnior V, Buzetti S \& Rodrigues RAF (2012) Preparo do solo e doses de nitrogênio em cobertura em arroz de terras altas. Pesquisa Agropecuária Tropical, 42:246253.

Guimarães CM, Fageria NK \& Barbosa Filho MP (2002) Como a planta de arroz se desenvolve. Piracicaba, Potafós. p.1-2. (Encarte das Informações Agronômicas, 9).

IAC - Instituto Agronômico de Campinas (2013) Cultivar IAC 202. Disponível em: <http://www.iac.sp.gov.br/areasdepesquisa/ graos/arroz.php>. Acessado em: 11 de maio de 2013.

Kamimura KM, Alves MC, Arf O \& Binotti FFS (2009) Propriedades físicas de um latossolo vermelho sob cultivo do arroz de terras altas em diferentes manejos do solo e água. Bragantia, 68:723-731.

Kaneko FH, Arf O, Gitti DC, Arf MV, Ferreira JP \& Buzetti S (2010) Mecanismos de abertura de sulcos, inoculação e adubação nitrogenada em feijoeiro em sistema plantio direto. Bragantia, 69:125-133.

Matsuo N \& Mochizuki T (2009) Growth and yield of six rice cultivars under three water-saving cultivations. Plant Production Science, 12:514-525.

Medeiros RD, Soares AA \& Guimarães RM (2005) Compactação do solo e manejo da água. I: Efeitos sobre a absorção de N, P, K, massa seca de raízes e parte aérea de plantas de arroz. Ciência e Agrotecnologia, 29:940-947.

-Rev. Ceres, Viçosa, v. 60, n.6, p. 802-810, nov/dez, 2013 
Mingotte FLC, Hanashiro RK \& Fornasieri Filho D (2012) Características físico-químicas do grão de cultivares de arroz em função da adubação nitrogenada. Semina - Ciências Agrárias, 33:2605-2618.

Nascente AS, Kluthcouski J, Rabelo RR, Oliveira P, Cobucci T \& Crusciol CAC (2011) Produtividade do arroz de terras altas em função do manejo do solo e da época de aplicação de nitrogênio. Pesquisa Agropecuária Tropical, 41:60-65.

Prabhu AS, Guimarães CM \& Silva GB (2002) Manejo da Brusone no arroz de terras altas. Santo Antônio de Goiás, Embrapa Arroz e Feijão. 6p. (Circular Técnica, 52).

Raij BV \& Quaggio JA (1983) Métodos de análises de solo para fins de fertilidade. Campinas, Instituto Agronômico. 31p. (Boletim Técnico, 81)

Reinert DJ, Albuquerque JÁ, Reichert JM, Aita C \& Andrada MMC (2008) Limites críticos de densidade do solo para o crescimento de raízes de plantas de cobertura em Argissolo Vermelho. Revista Brasileira de Ciência do Solo, 32:1805-1816.

Santos AP, Volpato CES \& Tourino MCC (2008) Desempenho de três semeadoras-adubadoras de plantio direto para a cultura do milho. Ciência e Agrotecnologia, 32:540-546.
Sarruge JR \& Haag HP (1974) Análises químicas em plantas. Piracicaba, ESALQ. 56p.

Seki AS, Benez SH \& Silva PRA (2012) Desempenho operacional de semeadura e produtividade do milho em plantio direto e cultivo mínimo. Energia na Agricultura, 27:01-18.

Silva EA, Soratto RP, Adriano E \& Biscaro GA (2009) Avaliação de cultivares de arroz de terras altas sob condições de sequeiro em Cassilândia, MS. Ciência e Agrotecnologia, 33:298-304.

Silva RP, Cora JE, Filho AC, Furlani CEA \& Lopes A (2008) Efeito da profundidade de semeadura e de rodas compactadoras submetidas a cargas verticais na temperatura e no teor de água do solo durante a germinação de sementes de milho. Ciência e Agrotecnologia, 32:929-937.

Trogello E, Modolo AJ, Carnieletto R, Kolling EM, Scarsi M \& Sgarbossa M (2012) Desenvolvimento inicial e produtividade da cultura do milho no sistema de integração lavoura-pecuária. Revista Ceres, 59:286-291.

Zonta EP \& Machado AA (1986) Sistema de análise estatística para microcomputadores - SANEST. Pelotas, UFPel. 150p. 